\title{
UMBATRA
}

Indonesian Journal of Anthropology

Volume 3 (2) Desember 2018 || eISSN 2528-1569

pISSN 2528-2115 || http://jurnal.unpad.ac.id/umbara

DOI : 10.24198/umbara.v3i2.22390

\section{Pengetahuan dan Praktik Konsumsi Herbal dan Rempah pada Masyarakat Semarang}

\author{
Yurisa Aprilia Athory ${ }^{1}$, Nico Andreas ${ }^{2}$ \\ ${ }^{1,2}$ Program Studi Antropologi, FISIP, Universitas Padjadjaran \\ 1yurisaaprilia@gmail.com
}

\begin{abstract}
Herbs and spices are common ingredients used by people for daily consumption and useful for maintaining a healthy body, preventing and treating various types of diseases. This research aims to see the knowledge of the people of Semarang in the Chinatown area in processing herbs and spices, as well as their practice in consuming these ingredients. This research was conducted using a qualitative approach, ethnographic design to describe in-depth and detail the knowledge and practice of Chinatown people in consuming herbs and spices. This research used an emic perspective: the perspective of the community. The results of this study found that the knowledge of the Chinatown community about herbs and spices is obtained from oral stories passed down from generation to generation (exemplified from parents to children), personal experiences, and stories of friends or relatives, and information obtained from the internet. Meanwhile, the practice of using herbs and spices is carried out to treat the illness or to prevent the disease.
\end{abstract}

Keywords: knowledge and practice, herbs and spices consumption, traditional medicine

\begin{abstract}
Abstrak
Herbal dan rempah adalah bahan-bahan yang umum digunakan oleh masyarakat untuk dikonsumsi sehari-hari dan bermanfaat untuk menjaga kesehatan tubuh, mencegah, dan mengobati berbagai jenis penyakit. Penelitan ini bertujuan untuk melihat pengetahuan masyarakat Semarang yang tinggal di kawasan sekitar pecinan dalam mengolah bahan-bahan herbal dan rempah, serta bagaimana praktik mereka dalam mengonsumsi bahan- bahan tersebut. Penelitian ini dilakukan dengan menggunakan pendekatan kualitatif, desain etnografi untuk mendeksripsikan secara mendalam dan rinci pengetahuan dan praktik konsumsi herbal dan rempah pada masyarakat yang tinggal di sekitar kawasan Pecinan Semarang dengan menggunakan perspektif emik yaitu perspektif dari masyarakat. Hasil penelitian ini menemukan bahwa pengetahuan masyarakat Pecinan Semarang mengenai tanaman herbal dan rempah diperoleh dari cerita lisan yang diwariskan secara turun-temurun (dicontohkan dari orang tua kepada anak), pengalaman pribadi, cerita teman atau kerabat, dan informasi yang diperoleh dari internet. Sementara, praktik penggunaan tanaman herbal dan rempah dilakukan sesuai dengan penyakit yang diderita atau
\end{abstract}


untuk tujuan mencegah penyakit.

Kata kunci: pengetahuan dan praktik, konsumsi herbal dan rempah, pengobatan tradisional

\section{Pendahuluan}

Penelitian ini membahas tentang pengetahuan dan praktik konsumsi herbal dan rempah pada masyarakat Semarang yang tinggal di sekitar kawasan Pecinan. Penelitian ini dilatarbelakangi oleh munculnya tren gaya hidup kembali ke alam (back to nature) di kalangan masyarakat yang ingin menerapkan gaya hidup sehat. Penggunaan bahan-bahan alami atau bahan yang berasal dari alam menjadi salah satu bagian dari gaya hidup ini. Oleh sebab itu, masyarakat pada saat ini mulai memanfaatkan kembali bahan-bahan yang berasal dari alam termasuk tumbuhan obat (herbal) dan rempah.

Tumbuh-tumbuhan herbal dan rempah menjadi salah satu unsur yang penting dalam kehidupan manusia karena memiliki berbagai manfaat, di antaranya sebagai sumber makanan dan pengobatan. Tanaman herbal dan rempahrempah merupakan sumber daya hayati yang sudah lama memainkan peran penting dalam kehidupan manusia. Tumbuhan herbal berasal dari kata herba yang berarti tumbuhan yang bermanfaat untuk menjaga vitalitas dan kesehatan tubuh serta penyembuhan aneka ragam penyakit (Hakim, 2015). Rempah adalah bagian dari tanaman yang berasal dari bagian batang, daun, kulit kayu, umbi, rimpang (rhizome), akar, biji, bunga atau bagianbagian tumbuhan lainnya. Pemanfaatan tanaman herbal dalam dunia kesehatan dapat diklasifikasikan ke dalam tiga kelompok yaitu sebagai fitofarmaka ${ }^{1}$, jamu, dan herbal terstandar. Selain tanaman herbal, ada pula rempah-rempah yang merupakan bagian dari tumbuhan yang digunakan sebagai bumbu penguat cita rasa, pengharum, dan pengawet makanan yang digunakan secara terbatas (Food and Agriculture Organization, 2005 dalam Hakim, 2015).

\footnotetext{
${ }^{1}$ Fitofarmaka adalah sediaan obat yang telah dibuktikan keamanan dan khasiatnya, serta memiliki bahan baku yang telah memenuhi persyaratan yang berlaku (Menteri Kesehatan Republik Indonesia, 1992).
} dasarkan literatur, kegiatan pengabdian kepada

Berdasarkan penelitian Rosmanita dan Saharuddin (2017) tersebut dapat disimpulkan bahwa penggunaan tanaman herbal tidak terlepas dari kebiasaan yang sudah berkembang di masyarakat secara turun-temurun. Hal ini menunjukkan bahwa faktor budaya turut berpengaruh pada pengetahuan dan praktik tanaman herbal. Oleh karena itu, pengetahuan dan praktik penggunaan tanaman herbal di setiap daerah berbeda-beda sesuai dengan kebiasaan yang berkembang di masing-masing daerah.

Penelitian ini dilakukan di kota Semarang. Ber- 
masyarakat yang berkaitan dengan pengelolaan tanaman herbal banyak dilakukan di kota ini. Kegiatan tersebut antara lain kegiatan pendampingan kegiatan wirausaha dengan memproduksi teh seduh dan celup berbahan daun kersen di kelurahan Lamper Tengah, Semarang (Sudarmanto, 2015). Berdasarkan kegiatan tersebut, dapat disimpulkan bahwa masyarakat Semarang pada umumnya memiliki sumber daya dan pengetahuan mengenai tanaman herbal yang dapat dikembangkan. Oleh karena itu, penelitian ini bertujuan untuk menggambarkan pengetahuan masyarakat tentang tanaman herbal dan rempah, khususnya pada masyarakat Semarang yang tinggal di sekitar kawasan pecinan. Selain itu, penelitian ini juga menggambarkan bagaimana praktik konsumsi dan herbal pada masyarakat Semarang yang tinggal di sekitar kawasan pecinan.

Penelitian ini diharapkan dapat memberikan informasi kepada pembaca tentang bagaimana pengetahuan dan praktik konsumsi herbal dan rempah pada masyarakat Semarang yang tinggal di sekitar kawasan pecinan. Penelitian ini juga diharapkan dapat memberikan data-data untuk berbagai pihak yang berkepentingan yang membutuhkan data mengenai kekayaan pengetahuan tanaman herbal dan rempah di Semarang. Selain itu, penelitian ini memiliki tujuan untuk melestarikan resep tradisional penggunaan herbal dan rempah di masyarakat pecinan Semarang agar tetap lestari sehingga dapat digunakan secara turun temurun untuk generasi yang akan datang.

\section{Kajian Pustaka}

\section{Etnomedisin}

Etnomedisin secara etimologi berasal dari kata ethno (etnis) dan medicine (obat). Hal ini menunjukkan bahwa etnomedisin sedikitnya berhubungan dengan dua hal yaitu etnis dan obat. Etnomedisin adalah salah satu bidang yang mengkaji hubungan antara manusia dan tumbuhan (etnobotani) yang menjelaskan perilaku atau budaya, dan pengetahuan lokal suatu masyarakat dalam menjaga kesehatanya. Pada praktiknya, pengobatan tradisional yang dilakukan seringkali menggunakan sumber hewani maupun hayati. Namun, penggunaan sumber daya hayati (tumbuhan) sebagai bahan obat memiliki frekuensi yang lebih sering digunakan.

Etnomedisin (ethnomedicine) berkaitan erat dengan budaya penyembuhan dan teori penyakit pada sebuah etnik (Kleinman, 1980 dalam Isniati, 2012). Etnomedisin merupakan bagian dari Antropologi Kesehatan yang mempelajari pengobatan tradisional, tidak hanya mempelajari sumber tertulis seperti Ayurveda, dan pengobatan cina, tetapi juga mempelajari praktik leluhur yang diturunkan oleh nenek moyang.

Persepsi masyarakat terhadap pemahaman kesehatan inilah yang lebih disebut dengan etnomedisin, namun dalam sistem yang tradisional. Pemahaman ini lebih dominan terjadi di daerah-daerah, terutama daerah pelosok. Pemanfaatan obat herbal biasanya berasal dari penelitian entomedisin yang dilakukan sebelum-sebelumnya, sehingga diketahui cara efektif dalam menemukan zat kimia atau bahan kimia yang terkandung dalam tumbuhan sebagai bahan obat (Purwanto, 2002 dalam Silalahi, 2016). Selain itu, tujuan adanya kajian etnomedisin adalah untuk mendapatkan pengetahuan baru mengenai bahan kimia dari suatu tumbuhan yang dapat digunakan untuk mengatasi penyakit baru. Etnomedisin juga dapat dijadikan oleh ilmuwan sebagai peluang untuk mendapatkan pengetahuan mengenai bahan obat dengan senyawa yang memiliki efek samping yang lebih kecil dibandingkan dengan obat yang terbuat dari bahan kimia.

Etnomedisin atau pengobatan secara tradisional berkaitan dengan herbal dan rempah. Hal tersebut karena rempah dan herbal dijadikan sebagai bahan dasar untuk pengobatan ini. Pengolahan herbal dan rempah pada pengobatan tradisional tidak perlu menggunakan teknologi yang sangat canggih. Hal ini karena pengobatan herbal dapat dilakukan hanya dengan mengandalkan pengetahuan tentang herbal dan rempah, serta 
khasiat atau efek sampingnya.

Di Indonesia, penelitian mengenai etnomedisin sudah dilakukan di beberapa tempat, antara lain penelitian yang dilakukan di Paramasan, Kalimantan Utara oleh Anshari, Martiana, Putra, dan Dyson (2015). Pada penelitian ini, etnomedisin dikenal dengan nama "babalian" dengan metode penyembuhan menggunakan obat herbal dan ritualisasi. Obat herbal ini terdiri dari beberapa macam akar atau daun yang sering disebut pelungsur; sementara ritual yang dilakukan terdiri atas dua ritual yang dikenal sebagai basambur dan baharagu. Basambur adalah ritual pengobatan dengan membacakan mantera kepada penderita sakit; sementara $b a$ haragu adalah ritual pengobatan yang dilakukan dengan melakukan permohonan oleh kepala suku kepada Tuhan sehingga pengganggu atau pemberi rasa sakit dapat menghilang (Anshari, Martiana, Putra, dan Dyson, 2015).

\section{Health Belief Model}

Health Belief Model digunakan untuk menjelaskan berbagai perilaku dan kaitannya dengan budaya atau kebiasaan yang berhubungan dengan kesehatan baik dalam hal pencegahan suatu penyakit dan juga respon perilaku untuk pengobatan suatu penyakit. Health BeliefModel dapat menjelaskan tentang perilaku pencegahan pada individu; dalam hal ini, Health Belief Model dapat menjelaskan mengapa individu mau mengambil suatu tindakan pencegahan ataupun mengontrol penyakit yang dideritanya. Konsep utama dari Health Belief Model adalah perilaku sehat ditentukan oleh kepercayaan individu atau persepsi tentang penyakit dan sarana yang tersedia untuk menghindari terjadinya suatu penyakit.

Health Belief Model (HBM) merupakan salah satu persepsi psikologis dalam menentukan perilaku akan tingkat kesadaran kesehatan. Selain itu, Health Belief Model adalah sebuah model kognitif yang dapat dipengaruhi oleh keadaan lingkungan sekitar. Keyakinan ini dapat mempengaruhi seorang individu dalam menentukan tindakan pencegahan ter- hadap penyakit (Corner, 2005; Glanz, et al., 2002, dalam Sakinah, 2017). Model ini timbul karena muncul masalah dalam masyarakat dalam menerima pencegahan yang dilakukan oleh pihak penyedia layanan.

Di dalam Health Belief Model, terdapat adanya model kepercayaan individu terhadap apa yang harus dilakukan dan apa yang tidak perlu dilakukan dalam menjaga perilaku kesehatan. Fanani (2014) menyatakan bahwa terdapat enam konstruk dalam teori Health Belief Model, yaitu:

\section{Perceived Susceptibility}

Konstruk ini berkaitan dengan risiko dan kerentanan yang akan terjadi pada seseorang. Dengan adanya konstruksi ini, maka seseorang akan memiliki pandangan dalam mengambil keputusan apakah dirinya memiliki risiko yang tinggi atau tidak pada sebuah penyakit.

2. Perceived Severity

Konstruk ini menjelaskan bagaimana tingkat krisis suatu penyakit. Hal ini berkaitan dengan pengetahuan individu terhadap sebuah penyakit, serta informasi yang didapatkan dan diketahui tentang penyakit yang dialaminya.

3. Perceived Benefits

Konstruk ini menjelaskan bagaimana seseorang memandang sebuah manfaat dan nilai yang akan didapat dari adanya hidup sehat yang mereka jalankan.

4. Perceived Barriers

Konstruk ini menjelaskan hambatan seseorang dalam merubah pola dan perilaku sehat yang berkaitan dengan keyakinan individu dalam menghadapi hambatan saat memelihara sebuah sikap atau perilaku. Di dalam hal ini, individu mempertimbangkan keuntungan dan konsekuensi mulai dari kefektifan, biaya, efek samping, kenyamanan, dan waktu.

5. Cues to Action

Isyarat bertindak yang mengarahkan seorang individu untuk dapat mendapatkan sebuah informasi dalam melakukan kebaikan. Contohnya yaitu media, dan sarana pendidikan kesehatan. 


\section{Self Afficacy}

Sebuah motivasi dalam mendukung hidup sehat sangatlah diperlukan. Self afficacy adalah sebuah kepercayaan individu terhadap kemampuan yang mendorong individu tersebut untuk melakukan suatu hal yang baik. Motivasi ini akan mendorong seseorang pada pencapaian yang diinginkan.

Penelitian terdahulu yang membahas topik serupa dengan penelitian ini antara lain penelitian Hakim et al. (2015) yang berjudul "Etnobotani Rempah-Rempah di Dusun Kopen Dukuh, Kabupaten Banyuwangi”. Penelitian itu menemukan bahwa terdapat 27 jenis rempahrempah yang ditanam di pekarangan rumah yang mempunyai manfaat dalam kehidupan sehari-hari bagi masyarakat di Dusun Kopeh Dukuh. Penelitian ini menunjukkan bahwa masyarakat di Dusun Kopeh Dukuh mempunyai pengetahuan terhadap jenis rempah-rempah yang ditanam di pekarangan rumah, serta memiliki pengetahuan tentang khasiat dari jenis rempah-rempah yang ditanam.

Pada penelitian yang dilakukan oleh Saepudin, Rusmana, dan Budiono (2015) tentang model manajemen pengetahuan sebagai bentuk diseminasi informasi tanaman obat herbal dan tanaman obat keluarga di Desa Cisondari Kecamatan Pasirjambu Kabupaten Bandung, menemukan bahwa masyarakat di sana pada dasarnya sudah memiliki pengetahuan tentang tanaman obat herbal dan tanaman obat keluarga. Hal tersebut dapat terlihat dari adanya tradisi masyarakat yang diturunkan dari leluhur berupa mempertahankan nilai dan menjadikan masa lalu sebagai rujukan kebenaran. Di dalam hal ini, pengetahuan mengenai tanaman obat herbal dan tanaman obat keluarga yang berasal dari pengalaman leluhur di masa lalu yang dijaga sampai saat ini masih diikuti karena apa yang leluhur anggap benar maka selamanya akan dianggap benar. Selain pengetahuan yang didapat dari leluhur, masyarakat di Desa Cisondari juga mendapatkan pengetahuan dengan melihat herbalis meramu ramuan. Akan tetapi, pengetahuan tersebut didapatkan tidak secara mendetail dan hanya untuk digunakan pada kehidupan sehari-hari. Pengetahuan tanaman obat herbal dan tanaman obat keluarga juga didapatkan dari personal experience, yaitu pengalaman pribadi masyarakat Desa Cisondari tentang obat herbal dan tanaman obat yang menjadi sumber pengetahuan yang efektif.

Pada penelitian yang berjudul "Eksplorasi Jenis dan Pemanfaatan Tumbuhan Obat pada Masyarakat Suku Muna di Permukiman Kota Wuna" yang dilakukan oleh Jumiarni, et al. (2017) menjelaskan bahwa pada Suku Muna terdapat 34 jenis tumbuhan yang berkhasiat sebagai obat. Bagian tumbuhan yang digunakan sebagai obat meliputi seluruh bagian tubuh tumbuhan atau hanya salah satu bagian saja (akar, batang, daun, bunga, buah dan biji). Keseluruhan jenis tumbuhan yang dikoleksi dapat dimanfaatkan untuk menyembuhkan 22 jenis penyakit dengan cara pemanfaatan yang beragam seperti direbus, dibakar ataupun diremas sebelum dipakai.

\section{Metode}

Penelitian ini dilakukan di kawasan Pecinan Semarang Jalan Gang Warung, Kauman, Kecamatan Semarang Tengah, Kota Semarang. Penelitian ini menggunakan metode penelitian kualitatif. Metode penelitian secara kulitatif adalah jenis penelitian yang bersifat deskriptif dan berusaha untuk menafsirkan dan memahami makna suatu peristiwa tertentu. Selain itu, penelitian menggunakan metode kualitatif bertujuan untuk memahami suatu objek secara mendalam. Penelitian secara kualitatif dilakukan untuk memperoleh makna pada suatu fenomena atau untuk menggambarkan suatu fenomena yang dijadikan sebagai topik penelitian. Metode penelitian kualitatif dipilih karena penelitian ini bertujuan untuk menggambarkan suatu fenomena secara detail

Penelitian ini menggunakan metode kualitatif dengan model etnografi. Model ini dipilih karena model etnografi tepat digunakan untuk mendeksripsikan secara mendalam dan rinci pengetahuan dan praktik konsumsi herbal 
dan rempah pada masyarakat yang tinggal di sekitar Kawasan Pecinan Semarang dengan menggunakan perspektif emik yaitu perspektif dari tineliti. Sampel yang digunakan yaitu diambil dengan cara pengambilan sampel secara purposive sampling. Purposive sampling memiliki kekuatan yaitu sampelyang dipilih sesuai dengan permasalahan penelitian yang akan dilakukan sehingga dapat menyediakan informasi sesuai dengan tujuan penelitian (Sugiyono, 2017). Sampel dipilih berdasarkan kriteria-kriteria tertentu agar dapat menjadi sampel yang yang menghasilkan data yang representatif. Kriteria tersebut di antaranya: sampel yang mempunyai pengetahuan tentang tentang herbal dan rempah, dan bersedia secara sukarela untuk memberikan informasi dan pengetahuan yang dimilikinya kepada peneliti.

Pengumpulan data dalam penelitian ini dilakukan dengan menggunakan teknik wawancara mendalam yang dilakukan secara langsung kepada masyarakat Semarang yang tinggal di sekitar kawasan Pecinan untuk mendapatkan informasi tentang pengetahuan dan cara konsumsi herbal dan rempah. Selain itu, peneliti mengambil data dengan teknik observasi partisipan yaitu mengamati lapangan atau tempat dilakukannya penelitian guna untuk memperkuat hasil atau data penelitian serta mencatat langsung hal-hal yang diperlukan untuk keperluan data penelitian.

Analisis data dalam penelitian ini dilakukan dengan menggunakan analisis data secara tematik model Miles dan Huberman (2012). Langkah-langkah analisis data dalam penelitian ini yaitu pengumpulan data (data collection), reduksi data (data reduction), penyajian data (data display), dan penarikan kesimpulan atau verifikasi (conclutions).

\section{Hasil dan Pembahasan}

\section{Pengetahuan Masyarakat tentang Herbal dan Rempah}

Masyarakat di daerah Pecinan Semarang mengklasifikasikan herbal dan rempah ke dalam beberapa kategori, yaitu: batang kulit kayu, umbi, akar, daun, kuncup bunga, umbi akar, biji, inti/biji, buah, dan rimpang. Masyarakat di sana memiliki pengetahuan yang cukup tentang keanekaragaman herbal dan rempah. Mereka mengenal beberapa jenis herbal dan rempah dan cara pemanfaatannya sebagai obat. Saat ini, masyarakat masih menggunakan herbal dan rempah untuk pengobatan ataupun pencegahan suatu penyakit. Pada penelitian ini, masyarakat Semarang yang tinggal di sekitar kawasan Pecinan mengenal semua jenis herbal dan rempah tersebut. Namun, hanya menggunakan beberapa jenis herbal dan rempah saja seperti kunir (Curcuma longa), kencur (Kaempferia galanga), daun salam (Syzygium polyanthum) dan daun sirsak (Annona muricata).

Masyarakat Semarang yang tinggal di sekitar kawasan Pecinan pada umumnya menggunakan herbal dan rempah untuk bumbu masakan. Mereka juga menggunakan herbal dan rempah sebagai alternatif untuk pengobatan tradisional. Mereka mendapatkan pengetahuan mengenai jenis-jenis herbal dan rempah secara lisan atau turun-temurun dari keluarga dan orang tua. Selain itu, pengetahuan tersebut juga didapatkan dari pengalaman atau didapatkan dari teman maupun kerabat. Pengetahuan itu kemudian diterapkan dalam kehidupan sehari-hari.

Masyarakat di kawasan pecinan Semarang beranggapan bahwa tumbuhan herbal dan rempah memiliki berbagai khasiat untuk kesehatan. Menurut mereka, herbal dan rempah dapat memberikan khasiat yang baik untuk kesehatan mereka dengan cara dikonsumsi secara rutin dan teratur. Namun, pengetahuan mereka mengenai efek samping dari tanaman herbal dan rempah yang mereka konsumsi masih terbatas. Mereka hanya beranggapan bahwa mengonsumsi herbal dan rempah yang dijadikan sebagai obat tradisional memiliki efek samping yang berakibat buruk pada tubuh jika terlalu banyak dikonsumsi. Selain itu, mereka juga beranggapan bahwa efek samping yang diakibatkan oleh obat tradisonal jauh lebih rendah dibandingkan dengan obatobatan kimia. Hal ini menjadi keunggulan obat 
tradisional dibandingkan obat-obatan kimia, walaupun obat tradisional memerlukan penggunaan yang lebih lama agar dapat dirasakan khasiatnya.

Khasiat yang dirasakan dengan mengonsumsi ramuan yang terbuat dari herbal dan rempah berbeda tergantung jenis yang digunakan. Masyarakat Pecinan Semarang pada umumnya mengonsumsi obat tradisional yang dianggap sesuai dengan kebutuhan tubuh mereka. Mereka biasanya mengonsumsi herbal dan rempah dengan cara mengolahnya menjadi ramuan khusus atau mengonsumsinya secara langsung (dikonsumsi mentah). Misal, Pak Cipto, salah satu masyarakat Pecinan yang bercerita bahwa ia memiliki penyakit asam urat. Ia rajin mengonsumsi daun salam (Syzygium polyanthum) karena dipercaya dapat menyembuhkan dan mengatasi penyakit asam urat yang dideritanya.

Pak Cipto memiliki pengetahuan mengenai daun salam yang dapat membantu penyembuhan penyakit asam urat yang dideritanya. Pengetahuannya ini ia dapatkan dari orangtuanya yang juga menderita asam urat, juga didapatkan dari media/internet. Ia menuturkan bahwa manfaat setelah mengonsumsi daun salam terasa ketika ia mengonsumi makanan yang berkolesterol tinggi. Sebelum ia mengonsumsi daun salam, tubuhnya terasa lebih berat apabila ia mengonsumsi makanan yang berkolesterol tinggi. Namun, setelah ia mengonsumsi daun salam, tubuhnya terasa lebih ringan.

Daun salam (Syzygium polyanthum) apabila dikonsumsi secara rutin dapat membantu proses penyembuhan penyakit asam urat. Selain mengobati penyakit asam urat, daun salam juga berkhasiat dalam membantu menyembuhkan penyakit diabetes karena mengontrol kadar gula darah dalam tubuh dan kolesterol. Daun Salam (Syzygium polyanthum) dikenal memiliki kandungan seperti flavonoid, tanin, dan minyak atsiri dengan kandungan minyak sitral dan eugenol yang diduga mampu menurunkan asam urat dalam darah. Minyak atsiri yang dikandung di dalam daun salam sebesar 0,05 persen bersifat antibakteri dan beraroma gurih. Unsur lain yang juga ditemukan dalam daun salam adalah sitral, eugenol, tanin dan flavonoid. Selain itu, daun salam (Syzygium polyanthum) bermanfaat sebagai peluruh kencing (diuretik) dan penghilang nyeri (analgetik). Sebagai diuretik, daun salam (Syzygium polyanthum) dapat memperbanyak produksi urin sehingga bisa menurunkan kadar asam urat darah (Andriani, 2018).

Selain mengonsumsi daun salam sebagai obat herbal, Pak Cipto juga mengonsumsi ramuan yang terbuat dari kunir (Curcuma longa). Pak Cipto menyatakan bahwa kunir dapat membantu masalah pencernaan. Selain itu, kunir juga memiliki khasiat untuk mencegah kanker apabila dikonsumsi secara rutin. Hal ini terbukti karena kunir (Curcuma longa) memiliki sebuah zat bernama kurkumin yang memberi warna kuning yang memiliki manfaat untuk mencegah dan mengobati kanker (Mutiah, 2015). Oleh karena itu, kandungan kurkumin ini dapat membantu mengobati sakit perut dan untuk pencegahan kanker.

Selain daun salam dan kunir, masyarakat Pecinan Semarang juga memanfaat daun sirsak (Annona muricata) sebagai salah satu jenis herbal yang dapat mencegah serta dapat menyembuhkan penyakit asam urat. Selain khasiatnya yang dapat mencegah penyakit asam urat, daun sirsak (Annona muricata) dikenal dengan khasiatnya yang manjur untuk menyembuhkan penyakit kanker. Kandungan acetoginin dalam daun sirsak (Annona muricata) mempunyai manfaat untuk menyerang sel kanker dengan aman dan efektif secara alami, tanpa rasa mual, berat badan turun, dan rambut rontok, seperti yang terjadi pada kemoterapi. Jenis kanker yang ampuh untuk dicegah oleh daun sirsak (Annona muricata) adalah kanker payudara (Ca mammae). Pak Cipto mengetahui informasi ini dari temannya yang bercerita bahwa daun sirsak (Annona muricata) yang dibuat menjadi ramuan dapat menghambat pertumbuhan sel kanker dan terasa pada badannya menjadi lebih sehat. 
Bahan herbal lainnya yang memiliki khasiat adalah kencur (Kaempferia galanga). Kencur (Kaempferia galanga) memiliki banyak khasiat di antaranya untuk menambah nafsu makan. Kencur (Kaempferia galanga) dikonsumsi dengan cara diolah menjadi ramuan yang biasanya dinamakan jamu beras kencur. Jamu beras kencur (Kaempferia galanga) merupakan ramuan yang terdiri dari kombinasi antara kencur (Kaempferia galanga), beras (Oryza sativa), gula merah, dan asam jawa (Tamarindus indica).

Selain tanaman herbal, masyarakat Pecinan Semarang juga mengenal jamu sebagai jenis minuman tradisional yang dapat dijadikan sebagai obat. Jamu merupakan minuman tradisional yang berbahan dasar herbal dan rempah yang diolah dengan resep tradisional memiliki berbagai bahan dasar seperti kunir (Curcuma longa), kencur (Kaempferia galanga), dan berbagai jenis herbal dan rempah yang dikombinasikan sehingga dapat memberikan berbagai manfaat yang luar biasa untuk kesehatan; baik untuk pengobatan maupun pencegahan suatu penyakit.

Pada dasarnya, masyarakat Semarang yang tinggal di sekitar kawasan Pecinan percaya bahwa dengan mengonsumsi herbal dan rempah, baik yang diolah menjadi ramuan atau dimakan langsung dapat memberikan khasiat bagi kesehatan tubuh. Misal, konsumsi daun sirsak (Annona muricata) dapat membantu penyembuhan penyakit asam urat; daun salam (Syzygium polyanthum) dapat menyembuhkan penyakit asam urat dan kolesterol, kunir (Curcuma longa) dapat digunakan untuk mengobati gangguan pencernaan; dan kencur (Kaempferia galanga) berkhasiat untuk menambah nafsu makan.

\section{Praktik Konsumsi Herbal dan Rempah}

Sebagian besar masyarakat Semarang yang tinggal di sekitar kawasan Pecinan mengonsumsi herbal dan rempah dengan mengolahnya menjadi minuman sejenis ramuan. Ramuan tersebut dibuat berdasarkan kebutuhan tubuh yang sedang mengalami sakit tertentu ataupun sesuai dengan jenis penyakit yang ingin dicegah atau diobati. Masyarakat Pecinan Semarang biasanya mengolah sendiri ramuah herbal dan rempah yang mereka konsumsi. Cara mengolah ramuan tersebut biasanya berdasarkan pengetahuan dan resep yang diterima secara turun-temurun dari orangtua maupun berdasarkan pengalaman teman.

Pak Cipto rutin mengonsumsi ramuan yang terbuat dari kunir (Curcuma longa). Ramuan ini dibuat dengan menggunakan 3 rimpang kunir (Curcuma longa) yang sudah dicuci dengan air yang mengalir. Setelah kunir dicuci dengan air bersih, kunir diparut, kemudian diperas hingga sari kunir berupa air yang berwarna kuning pekat keluar. Sari kunir tersebut lalu dimasukan ke dalam gelas dan airnya diminum. Ramuan sari kunir diminum tanpa ditambahkan air ataupun campuran lain seperti gula. Namun, apabila ia merasa tidak kuat dengan rasa dari sari kunir tersebut, ia menambahkan madu untuk memberikan rasa manis. Ramaun ini hanya diminum pada saat ia merasakan ada gangguan pencernaan.

Selain kunir, daun salam (Syzygium polyanthum) juga dikonsumsi dengan cara diolah menjadi jenis ramuan. Ramuan ini dibuat dengan cara merebus sebanyak 8-10 helai daun salam yang telah dicuci bersih ke dalam panci yang berisi air sekitar $1 / 2$ liter hingga airnya tersisa setengah panci (atau tersisa cukup untuk tiga gelas) dan warna airnya berubah. Setelah itu, air rebusan daun salam siap untuk diminum. Ramuan ini diminum dalam keadaan dingin. Rebusan daun salam ini dikonsumsi rutin pada saat akan tidur dan bangun tidur dan dikonsumsi sebelum makan. Khasiat yang dirasakan oleh Pak Cipto setelah ia mengonsumsi ramuan daun salam secara rutin adalah mencegah penyakit asam uratnya kambuh.

Selain mengonsumsi daun salam (Syzygium polyanthum), Pak Cipto juga terkadang meminum ramuan yang berbahan dasar daun sirsak (Annona muricata). Ramuan daun sirsak (Annona muricata) diolah dengan cara mencuci 10 lembar daun sirsak dengan air yang 
mengalir. Setelah itu, daun sirsak direbus dengan air tiga gelas sampai tersisa satu gelas saja. Ramuan ini diminum pada pagi hari dan diminum selagi hangat. Menurut Pak Cipto, ramuan rebusan daun sirsak (Annona muricata) dikenal memiliki khasiat untuk menyembuhkan dan mencegah kanker; sehingga Pak Cipto mengonsumsi minuuman ini sebagai pencegahan terhadap penyakit kanker. Selain itu, menurut Pak Cipto, ramuan rebusan daun sirsak (Annona muricata) memberikan efek nyaman terhadap tubuh.

Selain Pak Cipto, Ibu Marni yang juga merupakan salah satu masyarakat Pecinan Semarang memiliki pengetahuan tentang bahan-bahan herbal dan rempah. Ibu Marni mendapatkan pengetahuan mengenai herbal dan rempah karena ia sering mengonsumsi jamu, dan mendapatkan pengetahuan dari keluarganya secara turun-temurun. Selain itu, ia mendapatkan pengetahuan mengenai jamu ketika ia bekerja di perusahaan Sidomuncul. Ia menjelaskan bahwa ia rajin mengonsumsi jamu-jamuan untuk menjaga kesehatannya karena ia sudah lama menggeluti dunia jamu. Ia menambahkan bahwa dengan mengonsumsi jamu, maka tubuh akan tetap sehat dan terhindar dari berbagai penyakit. Jamu sendiri adalah ramuan yang terbuat dari bahan-bahan alami yang dibuat agar dapat dikonsumsi dan berkhasiat meningkatkan daya tahan tubuh, juga mengobati berbagai jenis penyakit. Jamu merupakan salah satu ramuan herbal yang dibuat melalui proses ekstrasi bahan-bahan herbal dan rempah. Selain itu, ada juga jamu yang dibuat tanpa melalui proses ekstraksi yang diambil dari bagianbagian tertentu dari beberapa jenis tanaman (seperti daun atau rimpang) yang diolah secara bersamaan tanpa melalui proses ekstraksi.

\section{Simpulan}

Berdasarkan temuan penelitian ini, Masyarakat Semarang yang tinggal di sekitar kawasan pecinan memiliki pengetahuan tentang tamanan herbal dan rempah yang beragam. Pengetahuan tersebut diperoleh dari cerita lisan yang diwariskan secara turun-temurun, pengalaman pribadi, dan berdasarkan cerita dari teman atau kerabat. Masyarakat yang tinggal di sekitar kawasan Pecinan mengolah bahan herbal menjadi ramuan obat tradisional yang mereka gunakan untuk mengobati penyakit yang sedang mereka derita atau untuk mencegah suatu penyakit. Seperti salah seorang masyarakat yang membuat ramuan tradisional yang berbahan dasar daun sirsak (Annona muricata) dan kunir (Curcuma longa). Daun sirsak digunakan oleh informan untuk mengobati penyakit asam urat yang ia derita. Selain itu, sebagian masyarakat juga mengonsumsi jamu yang berbahan dasar tanaman herbal dan rempah. Konsumsi ramuan maupun jamu pada masyarakat Pecinan Semarang didasarkan pada kebutuhan tubuh mereka, atau berdasarkan penyakit yang sedang mereka derita.

\section{Daftar Pustaka}

Andriani, A.. (2018). Pengaruh Pemberian Air Rebusan Daun Salam (Syzygium Polyanthum) Terhadap Penurunan Kadar Asam Urat. Jurnal Ipteks Terapan, 12(3), 112-119.

Anshari, M., Martiana, T., Putra, S. T., dan Dyson, L. (2015). Ethnomedicine of Dayak Paramasan Ethnic in the Meratus Mountains ( part-2 ): A Correlation of Spiritual Belief and Distress Level to Patient who had Done Ethnomedicine Treatment ( Pelungsur and Basambur ). 5(6), 40-42.

Anshari, M., Martiana, T., Putra, S. T., dan Dyson, L. (2015). Ethnomedicine of Dayak Paramasan Ethnic in the Meratus Mountains The Medicinal Plants for Diarrhea and Respiratory Disorder. 5(5), 139-147.

Cotton, C., Balick, M. J., dan Cox, P. A. (2006). Plants, People and Culture: The Science of Ethnobotany. Dalam The Geographical Journal (Vol. 164).

Fanani, S., dan Dewi, T, K. (2014). Health Belief Model pada Pasien Pengobatan Alternatif Supranatural dengan Bantuan Dukun. Jurnal Psikologi Klinis dan Kesehatan Mental. 3(1), 54-59.

Hakim, L., Batoro, J., dan Sukenti, K. (2015). Etnobotani Rempah-Rempah di Dusun Kopen Dukuh, Kabupaten Banyuwangi. Indonesian Journal of Environment and Sustainable Development, 6(2), 133-142. 
Isniati, I. (2012). Kesehatan Modern dengan Nuansa Budaya. Jurnal Kesehatan Masyarakat Andalas, 7(1), 39-44.

Jumiarni, W. O., dan Komalasari, O. (2017). Inventory of Medicines Plant as Utilized by Muna Tribe in Kota Wuna Settlement. Majalah Obat Tradisional (Traditional Medicine Journal), 22(1), 45-56.

Menteri Kesehatan Republik Indonesia. (1992). Keputusan Menteri Kesehatan Republik Indonesia Nomor 761/Menkes/SK/IX/1992 Tentang Pedoman Fitofarmaka.

Miles, M. B., dan Huberman, M. A. (2012). Analisis Data Kualitatif: Buku Sumber Tentang Metode-Metode Baru. Jakarta: UI Press.

Mutiah, R. (2015). Evidence Based Kurkumin dari Tanaman Kunyit (Curcuma longa) sebagai Terapi Kanker pada Pengobatan Modern. Jurnal Farma Sains, 1(1), 28-41.

Rosmanita, I., dan Saharuddin. (2017). Hubungan Tingkat Pengetahuan Lokal Masyarakat Desa Ciherang dengan Tingkat Pengelolaan Tanaman Obat Keluarga. Jurnal Sains Komunikasi Dan Pengembangan Masyarakat, 1(3), 359-378.

Saepudin, E., Rusmana, A., dan Budiono, A. (2015). Model Manajemen Pengetahuan sebagai Bentuk Diseminasi Informasi Tanaman Obat Herbal dan Tanaman Obat Keluarga (Studi Kasus di Desa Cisondari Kecamatan Pasirjambu Kabupaten Bandung). Sosiohumaniora, 17(2), 100-106.

Sakinah, Z. V. (2017). Aplikasi Health Belief Model dalam Menganalisis Perilaku Penggunaan Kacamata Pelindung. Jurnal Promkes: The Indonesian Journal of Health Promotion and Health Education, 5(1), 115 128.

Silalahi, M. (2016). Studi Etnomedisin Di Indonesia Dan Pendekatan Penelitiannya. Jurnal Dinamika Pendidikan, 9(3), 117-124.

Sudarmanto. (2015). Program Pendampingan Teh Seduh dan Celup dari Daun Kersen Guna Menumbuhkan Kreatifitas Wirausaha di Kelurahan Lamper Tengah Kecamatan Semarang Selatan Kota Semarang. Dimas: Jurnal Pemikiran Agama Untuk Pemberdayaan, 15(1), 71-84.

Sugiyono. (2017). Metode Penelitian Kuantitatif, Kualitatif, dan $R \& D$. Bandung: Alfabeta. 